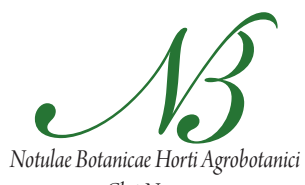

\title{
Microarray Analysis of the Transcriptome for Bacterial Wilt Resistance in Pepper (Capsicum annuum L.)
}

\author{
Jihyun HWANG ${ }^{1}$, Youngmi $\mathrm{CHOI}^{1}$, Jumsoon $\mathrm{KANG}^{1}$, Suntae KIM² \\ Myeongcheoul $\mathrm{CHO}^{3}$, Lucica MIHALTE ${ }^{4}$, Younghoon PARK ${ }^{*}$ \\ ${ }^{1}$ Pusan National University, Department of Horticultural Bioscience, Miryang, 627- \\ 706, Republic of Korea; ypark@pusan.ac.kr ("correspondingauthor) \\ ${ }^{2}$ Pusan National University, Miryang, Department of Plant Bioscience, 627-706, Republic of Korea \\ ${ }^{3}$ National Institute of Horticultural and Herbal Science, Rural Development Administration, Suwon, 441-440, Republic of Korea \\ ${ }^{4}$ University of Agricultural Sciences and Veterinary Medicine, 3-4 Mănăştur Street, Cluj-Napoca, Romania
}

\begin{abstract}
Ralstonia solanacearum causes one of the most common soil-borne vascular diseases of diverse plant species, including many solanaceous crops such as tomato and pepper. The resulting disease, bacterial wilt (BW), is devastating and difficult to control using conventional approaches. The aim of this study was to investigate the differentially expressed genes in pepper root systems in response to infection by $R$. solanacearum. DNA microarray (Capsicum annuum 135K Microarray v3.0 Gene Expression platform) analyses were performed using a susceptible genotype, 'Chilbok', and a resistant genotype, 'KC350', at 3 time points (1, 3, and 6 days post inoculation). It has been identified 115 resistance-specific genes (R-response genes) and 109 susceptibility-specific genes (S-response gene), which were up-regulated in 1 genotype, but down-regulated in the other genotype. Gene Ontology (GO) analysis for functional categorization indicated that many R-response genes were related to genes that function in xyloglucan biosynthesis and cell wall organization, while S-response genes were involved in the response to stress and cell death. The expression of genes encoding xyloglucan endotransglycosylase/ hydrolase (XTH) and $\beta$-galactosidase were verified by real-time RT-PCR at an early time point of $R$. solanacearum infection. The results supported the idea that rapidly induced $X T H$ expression in ' $\mathrm{KC} 350$ ' may play an important role in the restructuring and reinforcement of the cell wall and restrict bacterial movement in xylem vessels. In addition, induced expression of $\beta$-galactosidase in $R$. solanacearuminfected 'Chilbok' implied that degradation of the cell wall structure in vascular tissues by $\beta$-galactosidase might be an important factor facilitating $R$. solanacearum invasion of and movement in susceptible host plants.
\end{abstract}

Keywords: DNA chip, quantitative PCR, resistant genes, transcriptional profiling, tylose

\section{Introduction}

Bacterial wilt (BW) caused by the soil-born bacterial pathogen Ralstonia solanacearum (synonym Pseudomonas solanacearum) is one of the most prevalent plant diseases affecting hundreds of different species (Elphinstone, 2005; Hayward, 1991). The disease is distributed worldwide in tropical and subtropical humid countries, and the majority of agronomically important hosts include crops like tomato, chili and sweet pepper, potato, and eggplant, which belong to the Solanaceae and other non-solanaceous crops like banana, bean, and some ornamental plants (Buddenhagen, 1986). In the process of infection, $R$. solanacearum enters the host through either wounds or natural openings such as the site of secondary root emergence or the root tip, and spreads rapidly after intercellular growth throughout the vascular parenchyma and xylem elements (Wallis and Truter, 1978). Infected plants show internal symptoms of progressive discoloration of the vascular tis- sue, foliar epinasty, and collapse by wilting until complete necrosis (Kelman, 1953).

Plant genotypes resistant to BW have been reported for tomato, pepper, and bean. The mechanisms for natural resistance to $R$. solanacearum are related to limited growth and the restriction of pathogen movement within the host vascular systems. Histological analyses have demonstrated reinforced strength of parenchyma cell walls and pit membranes in xylem tissues and pathogen localization in the primary xylem tissues in stems in a resistant tomato cultivar (Nakaho et al., 2000). In a different study, limitation of bacterial spread in vessels in a resistant tomato genotype was associated with the production of tylose, which is a general, non-specific mechanism for inhibiting vascular pathogens or abiotic stresses like drought (Grimault et al., 1994).

Genetic inheritance of resistance was studied by progeny tests and QTL (quantitative trait loci) analysis using molecular markers. Polygenic patterns of resistance were 
50

found in Solanaceae species, while monogenic inheritance was reported for Arabidopsis thaliana (Deslandes et al., 2002). Genetic analysis in tomato revealed the involvement of several major QTL, and important roles for chromosome 4, 6, 8, and 12 in the control of strain-specific resistance. (Carmeille et al., 2006; Thoquet et al., 1996; Wang et al., 2000) A quantitative character governed by oligogenic inheritance was also reported for resistance to $R$. solanacearum in Capsicum pepper (Lafortune et al., 2005; Tran and Kim, 2010). Different modes of gene action that depended on pathogen isolates with different levels of virulence were reported in pepper, indicating the complicated inheritance of bacterial wilt resistance (Tran and Kim, 2010).

Our understanding of the molecular events involved in the establishment of resistance or susceptibility to $R$. $s o$ lanacearum is very limited. There have been few reports of studies on transcriptional profiling and analysis of gene function related to the host response to $R$. solanacearum. This can be attributed to the difficulties in inoculating root tissues with bacteria equally and simultaneously, as pointed out by Kiba et al. (2007), and the experimental limitations in assessing the expression profile of a large number of genes. DNA microarray is one of the most powerful technologies for analyzing gene expression in a wide range of biological systems. This technology enables scientist to perform a high sensitivity parallel screening of tens of thousands of genes to determine their expression profiles and quantitatively analyze a large amount of data (Brown and Botstein, 1999; Duggan et al., 1999)

The present study was conducted to investigate the expression profile of Capsicum pepper root tissue-specific genes that are responsive to inoculation with $R$. solanacearum using a pepper DNA microarray. The infectionspecific genes that were up- or down-regulated after inoculation were identified in BW-resistant and susceptible pepper cultivars, and their possible functional roles in the mechanism of resistance are discussed.

\section{Materials and methods}

\section{Plant materials and pathogen sources}

Two genotypes of chili pepper (Capsicum annuum L.), 'KC350'and 'Chilbok', were used for the microarray analysis. These genotypes were reported to be highly resistant and susceptible to different isolates (Miryang and Sangju, Korea) of $R$. solanacearum (Tran and Kim, 2010). For pathogen inoculation and induction of BW disease, the Miryang isolate of $R$. solanacearum, which is highly virulent, was used. Both the plant and the pathogen materials were obtained at Kyungpook National University, Korea.

\section{Plant inoculations and tissue collection}

For the control treatment (mock-inoculation) and the inoculation, 20 seeds per pepper genotype were sown in a 50 -cell plastic tray filled with vermiculite and grown in a growth chamber [16-h light $\left(126 \mu \mathrm{mol} \mathrm{m}{ }^{-2} \mathrm{~s}^{-1}\right) / 8$-h dark cycle at $28 \pm 2^{\circ} \mathrm{C}$ ] with occasional provision of nutrient solution. For the inoculations, the $R$. solanacearum isolate Miryang was cultured on TZC medium at $28^{\circ} \mathrm{C}$ for $48 \mathrm{~h}$, and then washed from the medium surface with deionized water. When the seedlings were at the 10- to 12-leaf stage, 1 plastic tray (inoculation treatment) was completely dipped in a bacterial suspension that was adjusted to A $600=0.6$ with a spectrophotometer $\left(1 \times 10^{8} \mathrm{CFU} /\right.$ $\mathrm{mL}$ ) for $1 \mathrm{~h}$ at room temperature. The other tray (mockinoculation control) was not inoculated, but was dipped in sterile distilled water under the same conditions. The plants were then placed back in the growth chamber, and sampled at 3 time points: 1, 3, and 6 days post inoculation (dpi). Five individual plants were randomly sampled for each treatment, and their roots were washed carefully using DEPC water and pooled into a single RNA sample for the microarray experiment. Harvested tissues were immediately frozen in liquid nitrogen and stored at $-70^{\circ} \mathrm{C}$ until total RNA extraction. For real-time RT-PCR verification of microarray data, seedling preparation and inoculation were conducted as described above, but independent from the microarray experiment. The individual plants were sampled at 3 time points, 6,12 , and $24 \mathrm{~h}$ post inoculation (hpi), for RT-PCR.

\section{Sample preparation and microarray procedure}

Total root RNA was extracted using the RNeasy Plant Mini Kit (QIAGEN, Germany) according to the manufacturer's instructions. The quality of RNA was measured using an Agilent 2100 Bioanalyzer (Agilent Technologies, USA). The Agilent 2100 Bioanalyzer provides a platform for electrophoresis of nucleic acids on a disposable chip. Each RNA sample $(1 \mu \mathrm{L})$ was loaded into an individual well on a chip and electrophoresed in the Bioanalyzer. The $18 \mathrm{~S}$ and $28 \mathrm{~S}$ ribosomal peaks were present in all samples as shown by an RNA integrity Number (RINs) from 8.0 to 10.0 , which verified the high quality of the RNA samples for the microarray analysis.

Briefly, double-stranded cDNA was synthesized using a Superscript Double-Stranded cDNA Synthesis Kit (Invitrogen, USA), and then Cy3-labeling of the target cDNA was performed. After labeling, the concentration of each sample was determined using a spectrophotometer, and $13 \mu \mathrm{g}$ of cDNA was used for the microarray hybridization. The sample was mixed with $19.5 \mu \mathrm{L}$ of $2 \times$ hybridization buffer (Nimblegen, USA), and then the volume was brought to $39 \mu \mathrm{L}$ with deionized water. Hybridization was performed using a MAUI chamber (Biomicro, USA) at $42^{\circ} \mathrm{C}$ for $16 \mathrm{~h}$ and then washed according to the instructions included with the Nimblege hybridization kit. The microarray experiments were performed with the pepper genome array (Capsicum annuum 135K Microarray v3.0 Gene Expression platform, GreenGene Bio, Korea), which was designed from 29,580 pepper unigenes. The hybridized microarray was scanned with a GenePix 4000B scanner (Axon, USA). 


\section{Analysis of microarray data}

The intensity values of different probe sets generated by Feature Extraction (FE) 9.5.3 software were imported into the GeneSpring GX7.3.1 software package (Agilent Technologies, USA). The relative expression levels of genes were calculated after normalization of the signal intensity values and outputted with the probe ID and GenBank descriptors to a Microsoft Excel data spreadsheet. Fold changes in the expression of each gene were determined based on the ratio of the signal intensities of the inoculated sample to mock-inoculated sample. Using the GeneSpring filter with the $\mathrm{n}$-fold-change tool, genes with a significant up- or down-regulated pattern were determined at a $P$ value of less than 0.05 by analysis of variance (ANOVA) parametric test with Benjamini-Hochberg multiple testing correction.

For the functional classification of genes, gene ontology (GO) analysis based on biological process and molecular function, and molecular function ontology analysis was performed using the Database for Annotation, Visualization, and Integrated Discovery (DAVID) tool on the web.

\section{Quantitative real-time PCR}

To validate the differential gene expression data obtained from the microarray, quantitative real-time PCR was performed on pools of RNA in triplicate. RNA was extracted from the pooled root tissues of 3 plants per treatment as described above. First-strand cDNA was synthesized from $1 \mu \mathrm{g}$ of total RNA with oligo $\mathrm{d}(\mathrm{T})$ primers using a Transcriptor First-Strand cDNA Synthesis Kit
(Roche Diagnostics, Germany) according to the manufacturer's instructions. Gene-specific primers for the xyloglucan endotransglycosylase/hydrolase, $\beta$-galactosidase, and actin genes were designed by comparison and alignment with all available related genes in the NCBI database.

Real-time RT-PCR was carried out using a LightCycler Instrument (Roche Diagnostics, Germany) and LightCycler FastStart DNA Master SYBR Green I (Roche Diagnostics, Burgess Hill, UK) following manufacturer's recommendations. Briefly, $1 \mu \mathrm{L}$ of the cDNA solution was used in a $10 \mu \mathrm{L}$ PCR reaction containing $1 \times$ SYBR Green I master mix and appropriate concentrations of $\mathrm{MgCl}_{2}$ and primers. Quantification of the relative changes in gene expression was performed using the LightCycler ${ }^{\circ} 480 \mathrm{sw}$ 1.5 (Roche Diagnostics, Germany).

\section{Results}

\section{Disease assessment of sample plants}

In previous bioassay experiments, disease symptoms were generally observed from $R$. solanacearum infected pepper plants at least 14 days after inoculation in a growth chamber. Therefore, it was impossible to validate the success of pathogen infection at the time of plant sampling for RNA extraction. To solve this problem, 5 plants per treatment were maintained under the same growth chamber condition until $15 \mathrm{dpi}$, and then the development of disease symptoms was assessed in those plants. All susceptible genotype plants showed typical BW symptoms, while resistant genotype plants remained healthy, which indicated successful pathogen inoculation.

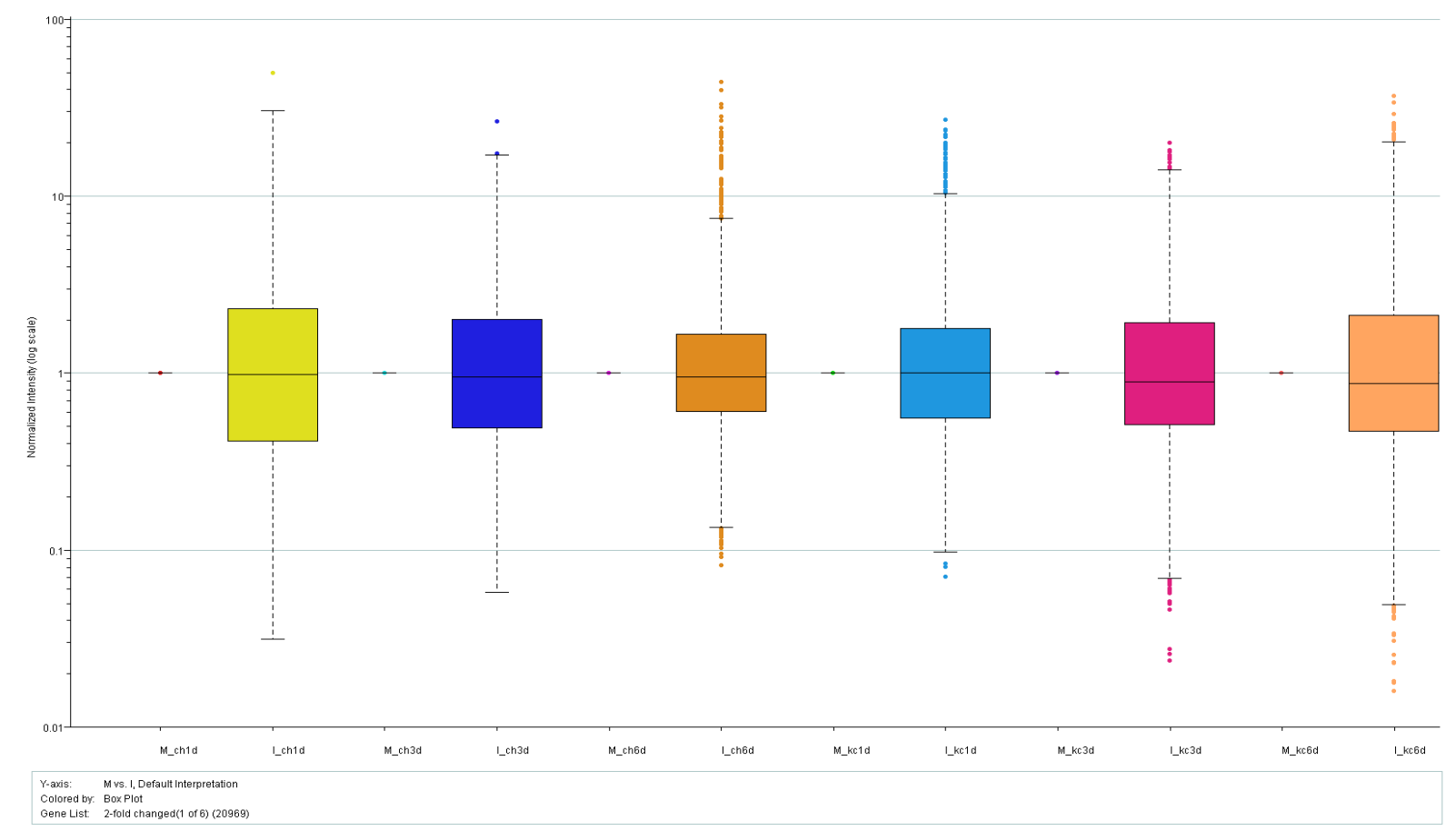

Fig. 1. Box plot displaying the log ratio distribution of the Capsicum annuum L. 135K microarray after normalization. The central box in a plot represents the interquartile range (IQR). The line in the middle of the box represents the median. Extreme values above the $75^{\text {th }}$ percentile and below the $25^{\text {th }}$ percentile were plotted invididually. Spots with extreme log ratios represent genes that appear to be strongly differentially expressed. I-inoculation; ch-'Chilbok'; kc-'KC350'; 1d, 1 dpi; 3d, 3 dpi; 6d, 6 dpi 
52

\section{Microarray data analysis}

Signal intensity data generated from each array were normalized in order to minimize and standardize non-biological variation, such as array-to-array variation, caused by handling or instrument inconsistencies. The box plot in Fig. 1 displays the array median value, upper and lower quartiles, largest/smallest non-outliers and outliers for each microarray in this experiment after normalization. Comparison of the probe intensities between 2 arrays, in which the same labeled RNA was applied, is displayed by scatter plots in Fig. 2.

Fold changes in the expression of each gene were determined based on the ratio of the normalized signal intensity of the inoculated sample to that of the mock-inoculated sample. It has been identified a number of differentially expressed genes in both the $R$. solanacearum-susceptible and resistant pepper genotypes. In the resistant genotype, 'KC350', the expression of 2,161 genes were up-regulat- ed more than 2-fold $(>2)$, while the expression of 2,225 genes was down-regulated more than 2 -fold $(<0.5)$ at any of 1,3 , and 6 dpi time points. In the susceptible genotype, 'Chilbok', the expression of 2,128 genes was up-regulated more than 2-fold $(>2)$, while the expression of 1,773 genes was down-regulated more than 2 -fold $(<0.5)$. To narrow down the number of genes possibly involved in the response to pathogen infestation, a selection strategy was employed; since the present experimental design did not include replication of DNA chip analysis for each time point, a statistical validation of the data, such as 2-way ANOVA, was not available for estimating the differential expression between the genotypes at each of the $3 \mathrm{dpi}$. Therefore, each time point was simply considered 1 of 3 technical replicates of the DNA chip analysis, and only genes for which the expression levels at all 3 of the time points were not significantly different within each genotype were ultimately selected.
Signal Distribution of Mchdpi_3/Mchdpi_1

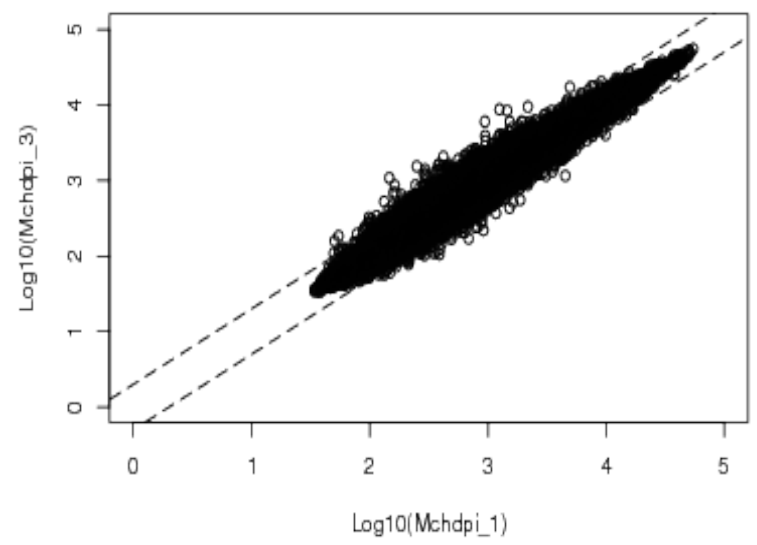

Signal Distribution of Mkcdpi_1/Mchdpi_1

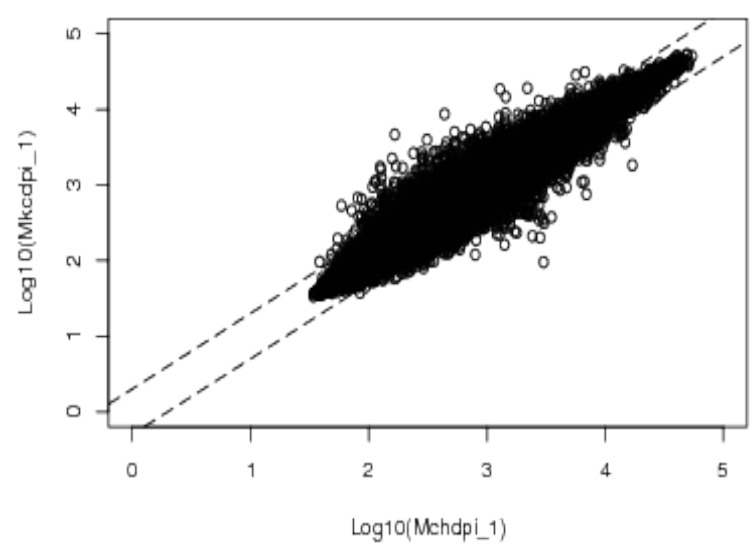

Signal Distribution of Mchdpi_6/Mchdpi_1

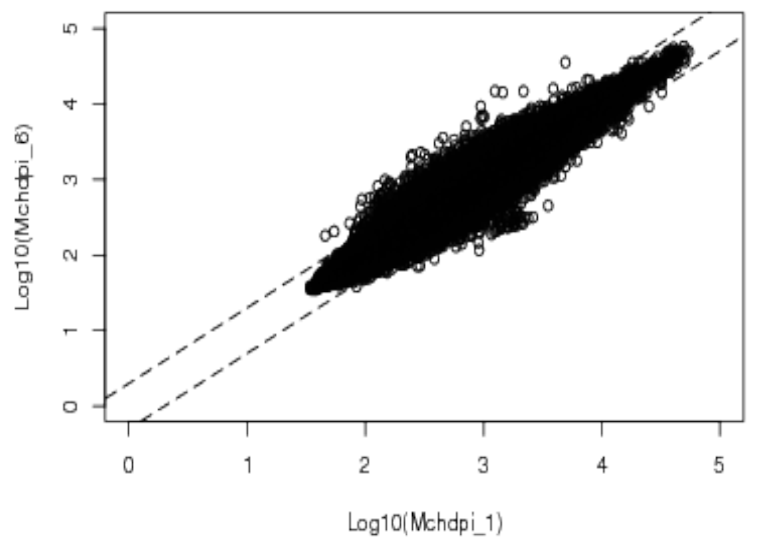

Signal Distribution of Mkcdpi_3/Mchdpi_1

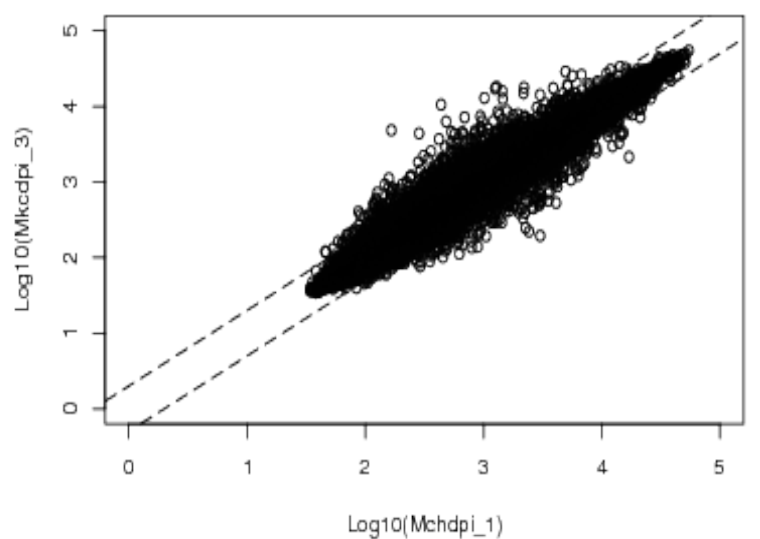

Fig. 2. Signal distribution of the Capsicum annuum L. 135K microarray. Signal intensities were log transformed with base 10. Intensities of Mchdpi_3, Mchdpi_6,Mkcdpi_1, and Mkcdpi_3 were compared with Mchdpi_1. The upper and lower dotted lines in each panel indicate the 2-fold increase and 2-fold decrease, respectively. M-mock-inoculation; ch-'Chilbok'; dpi-day post inoculation; kc-'KC350' 
In total, 224 genes that had significantly different expression between the 2 genotypes were detected by a 2-sample $t$-test; 115 resistance-specific genes and 109 susceptibility-specific genes were selected, which were upregulated in 1 genotype, but down-regulated in the other genotype. A hierarchical clustering algorithm was run for these most important genes in the present microarray measurements using MultiExperiment Viewer (http:// www.tm $4.0 \mathrm{rg} / \mathrm{mev} /$ ), and the result is displayed in Fig. 3. Among the 224 genes, 23 genes that exhibited a $>2$-fold change in at least 2 time points, were functionally identi$\mathrm{cal}$, and detected redundantly were selected and listed in Tab. 1.

Functional classification of differentially expressed genes

Functional annotation of the 224 genes was provided by the manufacturer of the pepper genome array (Green-
Gene Bio, Korea). Blastx of these genes with Arabidopsis thaliana retrieved 118 genes that showed highly homologous gene functions. Twenty-two genes with overlapping functions were eliminated, and the remaining 96 genes were included in the functional classification. The categories for the genes that were up-regulated in the resistant genotype but down-regulated in the susceptible genotype (R-response genes) included mainly proteins involved in metabolic process, response to stimuli, cell wall organization, external encapsulating structure organization, and carbohydrate metabolic process. The categories for genes that were up-regulated in the susceptible genotype but down-regulated in the resistant genotype $(S$-response genes) included proteins involved in the response to stress and abiotic stimulus and cell death. A complete list of the functional groups of genes is shown in Tab. 2 .

Tab. 1. Annotation of 24 candidate genes identified as significantly differentially expressed in Capsicum annuum L. root at 1, 3 , and $6 \mathrm{~d}$ post inoculation (dpi) with $R$. solanacearum. Only the 24 genes that were highly ranked in fold change and/or redundancy on microarray are shown. Genes with $>2$ fold changes are indicated by bold, while up-regulated genes with high redundancy are indicated by asterisks

\begin{tabular}{|c|c|c|c|c|c|c|c|}
\hline \multirow{2}{*}{$\begin{array}{l}\text { A. thaliana } \\
\text { gene } \\
\text { homologue }^{\text {a }}\end{array}$} & \multirow[b]{2}{*}{ Functional description of $A$. thaliana gene homologue } & \multicolumn{6}{|c|}{ Fold-change per treatment ${ }^{\mathrm{b}}$} \\
\hline & & $\mathrm{I}_{-} \overline{1}$ & $\mathrm{I}_{-} \overline{3} \mathrm{~d}$ & $\mathrm{I}_{\overline{6}}^{\mathrm{I}} \mathrm{d}$ & $\mathrm{kcld}_{-}^{\mathrm{I}}$ & $\mathrm{kc}_{-} \mathrm{I}_{\mathrm{d}}$ & $\mathrm{I}_{\mathrm{kc} \sigma \mathrm{d}}$ \\
\hline \multicolumn{8}{|c|}{ S-response gene } \\
\hline AT5G59120 & ATSBT4.13; subtilase & 3.55 & 2.29 & 2.02 & 0.90 & 0.69 & 1.11 \\
\hline AT5G56870* & BGAL4 (beta-galactosidase 4); beta-galactosidase & 2.47 & 2.06 & 1.07 & 0.70 & 0.73 & 0.87 \\
\hline AT3G58500 & PP2A-3: protein serine/threonine phosphatase & 2.43 & 2.66 & 2.03 & 0.98 & 0.90 & 0.79 \\
\hline AT2G25140 & Heat shock protein 98.7; ATP binding/ATPase & 2.82 & 2.32 & 1.22 & 0.99 & 0.63 & 0.54 \\
\hline AT3G12500 & ATHCHIB (BASIC CHITINASE); chitinase & 2.13 & 2.08 & 1.22 & 0.69 & 0.79 & 0.40 \\
\hline AT1G77050 & DEAD/DEAH box helicase, putative & 3.50 & 2.40 & 2.93 & 1.36 & 0.45 & 0.27 \\
\hline AT1G53350 & Disease resistance protein (CC-NBS-LRR class), putative & 3.78 & 4.70 & 1.18 & 0.69 & 0.66 & 0.59 \\
\hline AT3G17380 & Meprin and TRAF homology domain-containing protein & 1.95 & 2.42 & 2.29 & 0.78 & 1.24 & 0.60 \\
\hline AT5G20080 & NADH-cytochrome b5 reductase, putative & 2.78 & 2.16 & 1.72 & 0.71 & 1.09 & 0.81 \\
\hline AT5G19940 & Plastid-lipid associated protein PAP-related / fibrillin-related & 2.86 & 2.59 & 2.27 & 0.33 & 0.37 & 0.31 \\
\hline AT1G45207 & Remorin family protein & 2.45 & 2.20 & 1.60 & 0.54 & 0.47 & 0.52 \\
\hline AT3G61220 & Short-chain dehydrogenase/reductase (SDR) family protein & 4.13 & 3.50 & 4.70 & 0.62 & 0.66 & 0.98 \\
\hline \multicolumn{8}{|c|}{ R-response gene } \\
\hline AT2G01540 & C2 domain-containing protein & 0.62 & 0.66 & 0.98 & 3.33 & 3.45 & 3.44 \\
\hline AT1G62820 & Calmodulin, putative & 0.75 & 0.82 & 0.63 & 1.67 & 2.08 & 2.19 \\
\hline AT2G38540 & LP1 (nonspecific lipid transfer protein 1) & 0.63 & 0.82 & 0.99 & 2.62 & 2.11 & 2.61 \\
\hline AT4G04040 & Diphosphate-fructose-6-phosphate 1-phosphotransferase & 0.58 & 1.06 & 1.01 & 1.62 & 2.02 & 2.55 \\
\hline AT2G36690 & Oxidoreductase, 2OG-Fe(II) oxygenase family protein & 1.06 & 0.83 & 0.51 & 1.62 & 2.55 & 2.46 \\
\hline AT3G01280 & Porin, putative & 0.51 & 0.65 & 0.82 & 1.86 & 2.02 & 2.19 \\
\hline AT4G05180 & $\begin{array}{l}\text { PSBQ/PSBQ-2/PSII-Q (PHOTOSYSTEM II } \\
\text { SUBUNIT Q-2); calcium ion binding }\end{array}$ & 0.38 & 0.45 & 0.89 & 1.87 & 2.53 & 2.45 \\
\hline AT3G48200 & $\begin{array}{l}\text { Similar to hypothetical protein OsI_020499 } \\
\text { [Oryza sativa (indica cultivar-group)] }\end{array}$ & 0.28 & 0.43 & 0.64 & 1.19 & 2.11 & 2.04 \\
\hline AT5G57560* & TCH4 (TOUCH 4); hydrolase, acting on glycosyl bonds / xyloglucan & 0.38 & 0.48 & 0.77 & 1.48 & 2.13 & 2.17 \\
\hline AT5G06060 & Tropinone reductase, putative / tropine dehydrogenase, putative & 0.90 & 0.89 & 0.82 & 5.06 & 2.41 & 5.68 \\
\hline AT4G14130* & Xyloglucan endotransglycosylase 7; hydrolase, acting on glycosyl bonds & 0.34 & 1.01 & 1.19 & 3.02 & 2.97 & 3.11 \\
\hline AT3G23730* & Xyloglucan & 0.49 & 0.98 & 0.89 & 2.29 & 2.93 & 2.87 \\
\hline
\end{tabular}

${ }^{2} S$-response gene, a gene that was up-regulated in the susceptible genotype, 'Chilbok', but down-regulated in the resistant genotype 'KC350'; R-response gene, a gene that was up-regulated in the resistant genotype 'KC350', but down-regulated in the susceptible genotype 'Chilbok' ' $\mathrm{I}$-inoculation; ch-'Chilbok'; kc-'KC350'; $1 \mathrm{~d}-1 \mathrm{dpi}$; $3 \mathrm{~d}-3 \mathrm{dpi}$; 6d-6 dpi 
54

Tab. 2. Functional classification of genes that displayed significantly different expression in Capsicum annuum $\mathrm{L}$. roots inoculated with $R$. solanacearum

\begin{tabular}{lccc}
\hline \multicolumn{1}{c}{ Functional Class $^{\mathrm{a}}$} & Count & $\%$ & P-value \\
\hline \multicolumn{1}{c}{ S-response gene } & & & \\
\hline Response to stress & 10 & 31.2 & 0.017 \\
Response to abiotic stimulus & 6 & 18.7 & 0.056 \\
\hline Carbohydrate metabolic process & 5 & 15.6 & 0.086 \\
Programmed cell death & 3 & 9.3 & 0.059 \\
\hline Cell death & 3 & 9.3 & 0.074 \\
Death & 3 & 9.3 & 0.074 \\
\hline Positive regulation of response to stimulus & 2 & 6.2 & 0.093 \\
\hline \multicolumn{1}{c}{ R-response gene } & & & \\
\hline Metabolic process & 31 & 34.4 & 0.075 \\
\hline Response to stimulus & 15 & 16.6 & 0.098 \\
\hline Cell wall organization & 6 & 6.6 & $6.68 \mathrm{E}-04$ \\
\hline External encapsulating structure organization & 6 & 6.6 & $8.60 \mathrm{E}-04$ \\
Carbohydrate metabolic process & 6 & 6.6 & 0.095 \\
Cellular carbohydrate metabolic process & 5 & 5.5 & 0.041 \\
\hline Cellular glucan metabolic process & 4 & 4.4 & 0.003 \\
\hline Glucan metabolic process & 4 & 4.4 & 0.006 \\
\hline Cellular polysaccharide metabolic process & 4 & 4.4 & 0.007 \\
\hline Polysaccharide metabolic process & 4 & 4.4 & 0.018 \\
\hline Photosynthesis & 3 & 3.3 & 0.073 \\
\hline Photosynthesis, light harvesting & 2 & 2.2 & 0.078 \\
\hline
\end{tabular}

${ }^{a} \mathrm{~S}$-response gene, a gene that was up-regulated in the susceptible genotype 'Chilbok', but down-regulated in the resistant genotype 'KC350'; R-response gene, a gene that was up-regulated in the resistant genotype 'KC350', but down-regulated in the susceptible genotype 'Chilbok'

\section{Verification of the microarray data}

The expression pattern of genes that were significantly differentially expressed in the microarray data was verified by real-time RT-PCR on an independent set of biological replicates and RNA samples. Two genes, AT4G14130 (xyloglucan endotransglycosylase/ hydrolase, XTH) and AT5G56870 ( $\beta$-galactosidase), were selected as candidate $\mathrm{R}$-response and $\mathrm{S}$-response genes, respectively, since these genes were up-regulated with the highest redundancy. The primer sets for XTH (F: 5'-ATGACTGGGCAACACAAGGA-3', R: 5'TTGCAGCTGACCAAACACAA-3'), $\beta$-galactosidase (F: 5'-TTGCATGTTTTCGTCAATGG-3'， R: 5'GGGAGACCAACGGAAACACT-3'), and the actin gene (F: 5'-AGGGATGGGTCAAAAGGATG-3', R: 5'GAAGCACAGGGTGCTCTTCA-3') were designed based on conserved regions among homologous gene sequences.

In quantitative real-time PCR, transcript accumulation for XTH and $\beta$-galactosidase was observed in $R$. solanacearum-inoculated 'KC350' and 'Chilbok', respectively, within 24 hpi (Fig. 4). In comparison with the gene expression in mock-inoculated plants, $X T H$ was significantly up-regulated ( $>4$ fold) at 6 and $12 \mathrm{hpi} \mathrm{in} \mathrm{inoculated}$ 'KC350', while no significant change was observed at 24 hpi. The level of $X T H$ gene expression was much higher in 'KC350' compared to 'Chilbok' until 12 hpi; however, it

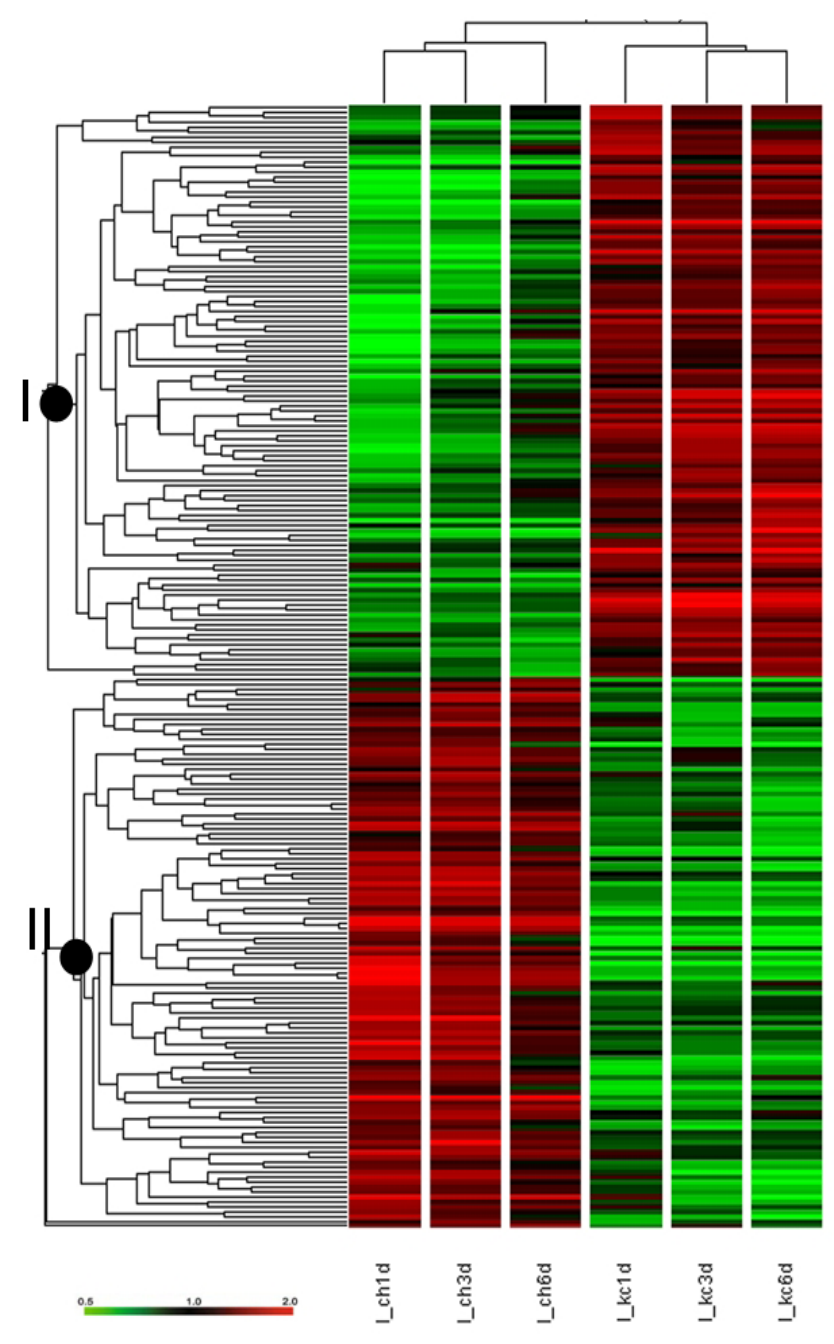

Fig. 3. Hierachical clustering of 224 genes with significantly different expression in Capsicum annuum L. roost 1, 3, and $6 \mathrm{~d}$ post inoculation (hpi) with $R$. solanacearum. The y-axis shows the list of genes and $\mathrm{X}$-axis shows the control and samples. Red fields indicate up-regulated genes (absolute difference) and green fields indicate the down-regulated genes. I-inoculation; ch-'Chilbok'; kc-'KC350'; 1d-1 dpi; 3d-3 dpi; 6d-6 dpi

decreased to a level similar to that in 'Chilbok' at $24 \mathrm{hpi}$. Expression of the $\beta$-galactosidase gene gradually increased up to 2.5 fold in 'Chilbok' until 24 hpi, while in 'KC350', it increased 2 fold until $12 \mathrm{hpi}$, but decreased to 0.5 fold at $24 \mathrm{hpi}$. The level of $\beta$-galactosidase gene expression in 'Chilbok' was somewhat higher than that in 'KC350' until 6 hpi; however, it increased significantly (up to 5 fold) in 'Chilbok' at 24 hpi. The changes in the expression of these genes were consistent with the results from the microarray analysis, which showed 3.0- and 2.5-fold changes compared to mock-inoculated plants at $1 \mathrm{dpi}$.

\section{Discussion}

In the present study, a significant increase in xyloglucan endotransglycosylase/hydrolase (XTH) gene expression was observed when a BW-resistant genotype, 'KC350', 

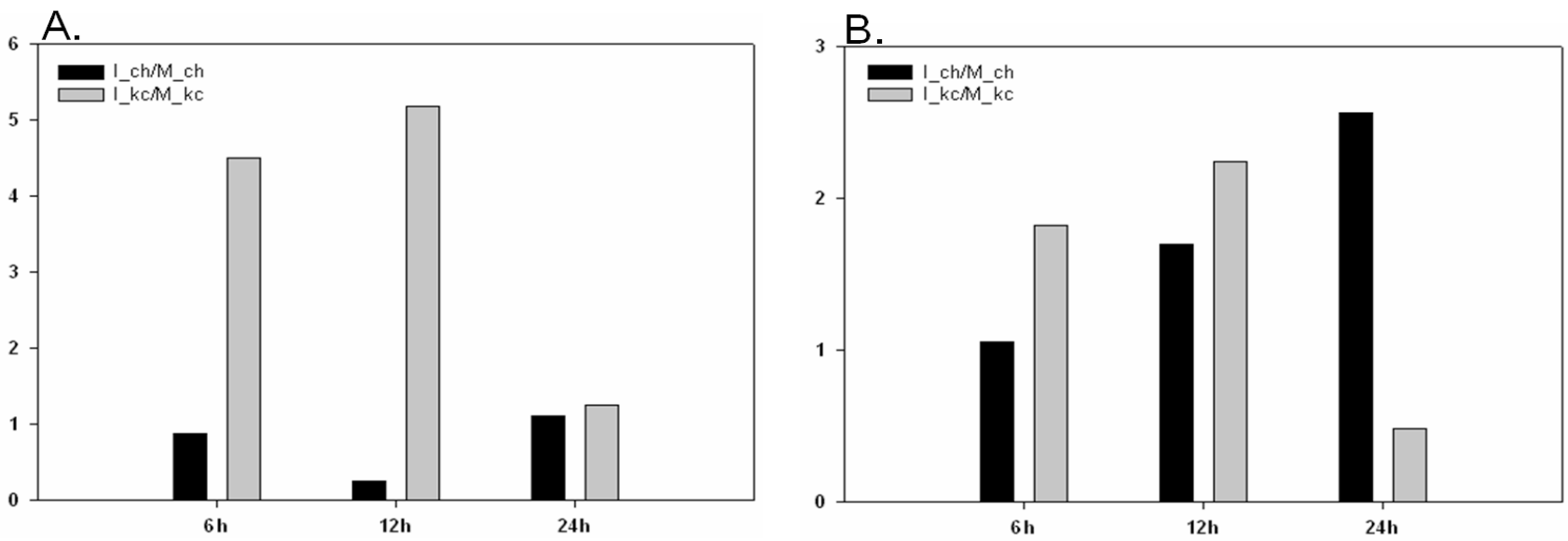

Fig. 4. Quantitative real-time PCR analysis of XTH (A) and $\beta$-galactosidase (B) mRNA levels (Y-axis) in Capsicum annuum L. roots at 6, 12, and 24 h post inoculation (hpi) with $R$. solanacearum. I-inoculation; M-mock-inoculation; ch-'Chilbok'; kc-'KC350'

was inoculated with $R$. solanacearum. The role of XTH in the host response to $\mathrm{BW}$ pathogen infection has not been previously reported. XTHs have been implicated in many aspects of cell wall biosynthesis and have been proposed to function in distinct roles during cell wall expansion. These enzymes are considered essential for certain aspects of cell wall remodeling, including cell wall architecture, strength, and extensibility (Fry, 1989; Nishitani and Tominaga, 1992). XTHs catalyze the breakdown and reformation of xyloglucan crosslinks, and are involved in the transfer of xyloglucan chains to hemicellulose (Campbell and Braam, 1999; Fry et al., 1992). This integrational transglycosylation contributes to cell wall assembly, and the resulting extensive xyloglucan-cellulose network is the major tensionbearing structure in the primary cell wall during controlled cell expansion (Nishitani, 1998).

In addition, XTH activity in xylem and phloem fibers during secondary wall formation has been demonstrated in poplar stems (Bourquin et al., 2002). This study reported that XTH plays a role in restructuring the primary wall at the time when secondary wall layers are deposited, probably creating and reinforcing the connections between the primary and secondary wall layers. Bourquin et al. (2002) demonstrated that the expression and activity of XTHs are often correlated with cell elongation, for example, in tomato hypocotyls (Catala et al., 1997), maize root tips (Pritchard et al., 1993), and Arabidopsis root tips (Vissenberg et al., 2000).

Anatomical changes in the cell wall induced by XTHs are one part of the defense response (Vorwerk et al., 2004). A role for XTHs in the defense reactions associated with the incompatible tomato-Cuscuta (dodder) interaction has also been reported. An additional example of induced cell expansion by XTHs is associated with the incompatible interaction of tomato with Cuscuta in the hypodermis cells of the host (Albert et al., 2004; Ihl et al., 1988; Sahm et al., 1995). The corresponding mRNA of this tomato $\mathrm{XTH}$ gene $(\mathrm{LeXTHI})$ accumulated $6 \mathrm{~h}$ after attachment of the parasite. XTHs (TXH33) were previously found to systemically accumulate in celery (Apium graveolens) phloem following infestation with the aphid Myzus persicae (Divol et al., 2007). The role of XTH33 in protecting plants against aphids implied that cell modification could alter aphids' preference for a particular plant.

Histological analyses demonstrated that the limitation of bacterial spread associated with resistance of tomato to BW was attributed to an induced, non-specific, physical barrier (Grimault et al., 1994; Nakaho et al., 2000). The inner electron-dense layer of the cell walls of parenchyma cells and vessels was thicker and more conspicuous in the xylem tissues of the infected resistant cultivar (LS-89) than in the xylem of the infected susceptible cultivar (Ponderosa) or mock-inoculated plants. These results indicated that $R$. solanacearum moves from vessel to vessel in infected tissues through degenerated pit membranes, and that restricted movement in xylem tissues was a characteristic feature in LS-89. This limitation in bacterial movement may be related to the thickening and reinforcing strength in the cell wall and pit membranes and accumulation of electron-dense materials around pits, in vessels, and in parenchyma cells (Nakaho et al., 2000).

Another common and efficient response to vascular microbes is differentiation of tyloses from vessel-associated parenchyma cells. Tyloses are outgrowths on the parenchyma cells of xylem vessels that occur as a result of cell growth and elongation. Limitation of bacterial spread in the BWresistant cultivar correlated with the production of tyloses, gums, and deposits (Grimault et al., 1994). In comparative histology, tyloses occluded both the colonized and contiguous vessels, limiting bacterial spread. In contrast, in the wilting susceptible cultivars, no tyloses were observed in the colonized vessels, and bacterial spread was not limited. In tomato xylem tissues, accumulation of electron-dense material as well as the production of tyloses and gums has been reported as general mechanisms of resistance to vascular fungal pathogens (Beckman et al., 1989). These physical barriers to vascular pathogens in tomato may be naturally non-specific or common responses. 
56

Although no histological assay or transcriptional investigation has been reported for the plant-pathogen interaction of $\mathrm{BW}$ in pepper, the resistance response to $R$. solanacearum observed in the pepper cultivar 'KC350' may be attributed to the defense mechanisms described above. Rapidly induced $X T H$ expression in 'KC350' may play an important role in the restructuring and reinforcement of the cell wall and/or the formation of tyloses and gums in xylem vessels, which result in limitation of bacterial movement and spread. In addition, as shown in the functional classification, the numerous R-response genes that are involved in xyloglucan biosynthesis suggest that its role is related to the resistance response to $R$. solanacearum.

Although expression of the $\beta$-galactosidase gene was induced in response to $R$. solanacearum infection in the susceptible pepper genotype, it is unclear how this gene plays a role in the host-pathogen interaction in BW. The $\beta$-galactosidase enzyme has been detected in a wide range of plants, and its activity is characterized by the ability to hydrolyze terminal, non-reducing $\beta$-D-galactosyl residues from $\beta$-galactoside polymers (Smith et al., 1998). Studies have shown that this enzyme may be involved in releasing stored energy for rapid growth, degrading cell wall components during senescence, and releasing free galactose during metabolic recycling of galactolipids, glycoproteins, and cell wall components in many ripening fruit (Gross and Sams, 1984; Kim et al., 1991; Seymour and Gross, 1996). Although further investigation is necessary, the induction of $\beta$-galactosidase gene expression may be important for $R$. solanacearum to destroy the cell wall structure of the vascular tissues and facilitate its invasion and movement in the host plants. The function of many $\mathrm{S}$-response genes, as shown in the functional categorization, also implied that induction of cell death may be one of the mechanisms employed by $R$. solanacearum during colonization of the host.

\section{Acknowledgements}

This study was carried out with the support of "Research Cooperating Program for Agricultural Science and Technology Development (Project No. PJ006581102011)", RDA, Republic of Korea.

\section{References}

Albert M, Werner M, Proksch P, Fry SC, Kaldenhoff R (2004). The cell wall-modifying xyloglucan endotransglycosylase/ hydrolase $L e X T H 1$ is expressed during the defence reaction of tomato against the plant parasite Cuscuta reflexa. Plant Biol 6:402-407.

Beckman CH, Verdier PA, Mueller WC (1989). A system of defence in depth provided by vascular parenchyma cells of tomato in response to vascular infection with Fusarium oxysporum f.sp. lycopersici. Physiol Mol Plant Pathol 34:227239.
Bourquin V, Nishikubo N, Abe H, Brumer H, Denman S, Eklund M, Christiernin M, Teeri TT, Sundberg B, Mellerowicz EJ (2002). Xyloglucan endotransglycosylases have a function during the formation of secondary cell walls of vascular tissues. Plant Cell 14:3073-3088.

Brown PO, Botstein D (1999). Exploring the new world of the genome with DNA microarrays. Nat Genet 21:33-37.

Buddenhagen IW (1986). Bacterial wilt revisited, p. 126-139. In: Persley GJ (Ed). Bacterial wilt in Asia and the South Pacific. ACIAR Proceedings, ACIAR, Camberra.

Carmeille A, Caranta C, Dintinger J, Prior P, Luisetti J, Besse P (2006). Identification of QTLs for Ralstonia solanacearum race 3-phylotype resistance in tomato. Theor Appl Genet 113:110-121.

Campbell P, Braam J (1999). Xyloglucan endotransglycosylases: diversity of genes, enzymes and potential wall-modifying functions. Trends Plant Sci 4:361-366.

Catala C, Rose JK, Bennett AB (1997). Auxin regulation and spatial localization of an endo-1,4- $\beta$-d-glucanase and a xyloglucan endotransglycosylase in expanding tomato hypocotyls. Plant J 12:417-426.

Deslandes L, Olivier J, Theulieres F, Hirsch J, Feng DX, BittnerEddy P, Beynon J, Marco Y (2002). Resistance to Ralstonia Solanacearum in Arabidopsis Thaliana is conferred by the recessive $R R S 1-R$ gene, a member of a novel family of resistance genes. Proc Natl Acad Sci 99:2404-2409.

Divol F, Vilaine F, Thibivilliers S, Kusiak C, Sauge MH, Dinant S (2007). Involvement of the xyloglucan endotransglycosylase/ hydrolases encoded by celery XTH1 and Arabidopsis XTH33 in the phloem response to aphids. Plant Cell Environ 30:187-201.

Duggan DJ, Bittner M, Chen Y, Meltzer P, Trent JM (1999). Expression profiling using cDNA microarrays. Nat Genet 21:10-14.

Elphinstone JG (2005). The current bacterial wilt situation: a global overview. In: Allen C, Prior P, Hayward AC (Eds.). Bacterial wilt disease and the Ralstonia solanacearum species complex. St. Paul, MN, APS Press.

Fry SC (1989). Cellulases, hemicelluloses and auxin-stimulated growth: a possible relationship. Physiol Plant 75:532-536.

Fry SC, Smith RC, Renwich KF, Martin DJ, Hodge SK, Matthews KJ (1992). Xyloglucan endotransglycosylase a new wall-loosening enzyme activity from plants. Biochem J 282:821-828.

Grimault V, Gelie B, Lemattre M, Prior P, Schmit J (1994). Comparative histology of resistant and susceptible tomato cultivars infected by Pseudomonas solanacearum. Physiol Mol Plant Pathol 44:105-123.

Gross KC, Sams CE (1984). Changes in cell wall neutral sugar composition during fruit ripening: a species survey. Phytochem 23: 2457-2461.

Hayward AC (1991). Biology and epidemiology of bacterial wilt 
caused by Pseudomonas solanacearum. Ann Rev Phytopathol 29:65-87.

Ihl B, Tutakhil N, Hagen A, Jacob F (1988). Studien and Cuscuta reflexa Roxb. Zum Abwehrmechanismus von Lycopersicon esculentum Mill. Flora 181:383-393.

Kelman A (1953). The bacterial wilt caused by Pseudomonas solanacearum. A literature review and bibliography. Raleigh, N.C., North Carolina State College.

Kiba A, Maimbo M, Kanda A, Tomiyama H, Ohnishi K, Hikichi Y (2007). Isolation and expression analysis of candidate genes related to Ralstonia solanacearum-tobaco interaction. Plant Biotech 24:409-416.

Kim J, Gross KC, Solomos T (1991). Galactose metabolism and ethylene production during development and ripening of tomato fruit. Postharv Biol Technol 1: 67-80.

Lafortune D, Beramis M, Daubeze AM, Boissot N, Palloix A (2005). Partial resistance of pepper to bacterial wilt is oligogenic and stable under tropical conditions. Plant Dis 89:501-506.

Mangin B, Thoquet P, Olivier J, Grimsley NH (1999). Temporal and multiple Quantitative Trait Loci analyses of resistance to bacterial wilt in tomato permit the resolution of linked loci. Genetics 151:1165-1172.

Minic Z (2008). Physiological roles of plant gylcoside hydrolases. Planta 227:723-740.

Nakaho K, Hibino H, Miyagawa H (2000). Possible mechanisms limiting movement of Ralstonia solanacearum in resistant tomato tissues. Phytopathol 148:191-190.

Nishitani K, Tominaga R (1992). Endoxyloglucan transferase, a novel class of glycosyltransferase that catalyzes transfer of a segment of xyloglucan molecule to another xyloglucan molecule. J Biol Chem 267:21058-21064.

Nishitani K (1998). Construction and restructuring of the cellulose xyloglucan framework in the apoplast as mediated by the xyloglucan-related protein family-a hypothetical scheme. J Plant Res 111:159-166.

Pritchard J, Hetherington PR, Fry SC, Tomos AD (1993). Xyloglucan endotransglycosylase activity, microfibril orientation and the profiles of cell-wall properties along growing regions of maize roots. J Exp Bot 44:1281-1289.

Sahm A, Pfanz H, Grunsfelder M, Czygan FC, Proksch P (1995). Anatomy and phenylpropanoid metabolism in the incompatible interaction of Lycopersicon esculentum and Cuscuta reflexa. Bot Acta 108:358-364.
Seymour GB, Gross KC (1996). Cell wall disassembly and fruit softening. Postharvest News Info 7: 45N-52N.

Smith DL, Starrett DA, Gross KC (1998). A gene coding for tomato fruit b-galactosidase II is expressed during fruit ripening. Cloning, characterization, and expression pattern. Plant Physiol 11:417-423.

Thoquet P, Olivier J, Sperisen C, Rogowsky P, Prior P, Anais G, Mangin B, Bazin B, Nazer R, Grimsley N (1996). Polygenic resistance of tomato plants to bacterial wilt in the French West Indies. Mol Plant Microbe Interact 9:837-842.

Tran NH, Kim BS (2010). Inheritance of resistance to bacterial wilt (Ralstonia solancearum) in pepper (Capsicum annuum L.). Hort Environ Biotechnol 51:431-439.

Turner M, Jauneau A, Genin S, Tavella MJ, Vailleau F, Gentzbittel L, Jardinaud MF (2009). Dissection of bacterial wilt on Medicago truncatula revealed two type III secretion system effectors acting on root infection process and disease development. Plant Physiol 150:1713-1722.

Vailleau F, Sartorel E, Jardinaud MF, Chardon F, Genin S, Huguet T, Gentzbittel L, Petitprez M (2007). Characterization of the interaction between the bacterial wilt pathogen Ralstonia solanacearum and the model legume plant Medicago truncatula. Mol Plant Microbe Interact 20:159-167.

Vissenberg K, Martinez-Vilchez IM, Verbelen, JP, Miller JG, Fry SC (2000). In vivo co-localization of xyloglucan endotransglycosylase activity and its donor substrate in the elongation zone of Arabidopsis root. The Plant Cell 12:12991337.

Vorwerk S, Somerville S, Somerville C (2004). The role of plant cell wall polysaccharide composition in disease resistance. Trends Plant Sci 9:203-209.

Wallis FM, Truter SJ (1978). Histopathology of tomato plants infected with Pseudomonas solanacearum with emphasis on ultrastructure. Physio Plant Pathol 13:307-317.

Wang JF, Olivier J, Thoquet P, Mangin B, Sauviac L, Grimsley NH (2000). Resistance of tomato line Hawaii7996 to Ralstonia solanacearum Pss4 in Taiwan is controlled mainly by a major strain-specific locus. Mol Plant Microbe Interact 13:6-13. 